\title{
Motivational Interactions: a client-centred engagement strategy in Australian accident compensation schemes
}

Arthur Papagiannis

AP Psychology \& Consulting, South Yarra VIC 3141, Australia. arthur@psychology-consulting.com

Motivational interactions is based on the foundations of "Motivational interviewing" and the "Transtheoretical Model of Behaviour Change", Which is widely recognised as an important engagement strategy for people working in a case management capacity- working with a range of injured client/worker needs pertaining to resistance, ambivalence to change, motivation, development and return to work. The quality of the working relationship between the worker and client is said to be a significant predictor of outcomes for a client. Evidence has indicated that a collaborative positive client centred engagement that is responsive to the change process of individuals is a reliable indicator of outcomes in a range of mental health, psychosocial and physical injury issues e.g. stress, depression, anxiety, physical injury, disability, with positive relationships being correlated with better Return to work/Life outcomes. 